\title{
SpyGlass percutaneous transhepatic cholangioscopy-guided lithotripsy of a large intrahepatic stone
}

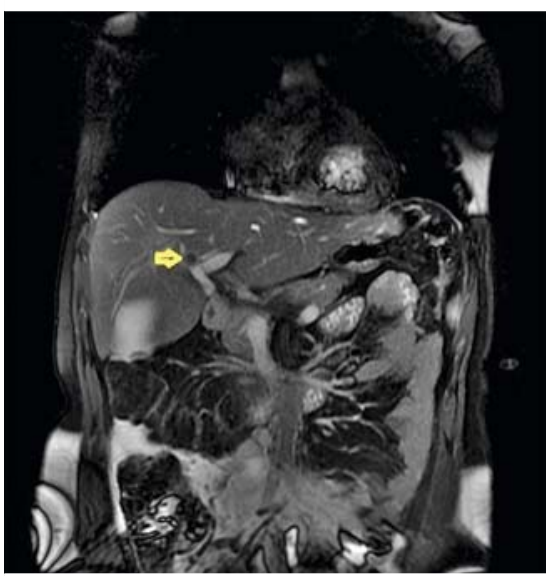

- Fig. 1 Intrahepatic stone (arrow) observed at magnetic resonance cholangiopancreatography.

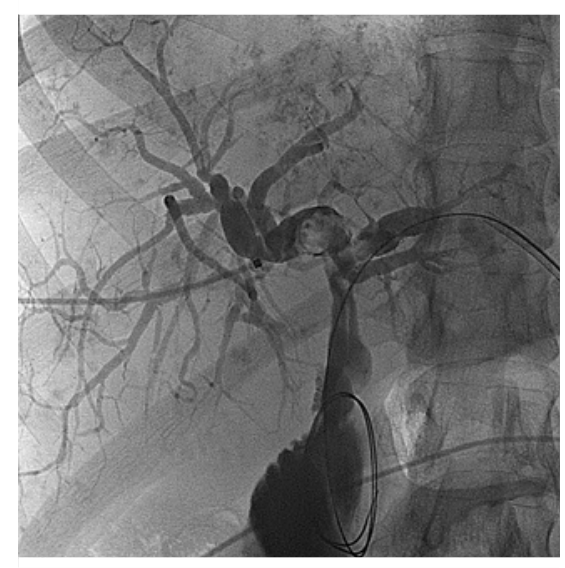

- Fig. 2 Impacted biliary stone in the right hepatic duct observed during percutaneous transhepatic cholangiography.

Occasionally, biliary stone management can be really challenging, depending on location, size, number, altered anatomy, and presence of strictures [1]. Although different approaches can be used in this setting, such as endoscopic retrograde cholangiopancreatography (ERCP), percutaneous transhepatic biliary drainage (PTBD), and extracorporeal shock wave lithotripsy or surgery [2], more complex cases may require management using a combination of techniques [3-5].

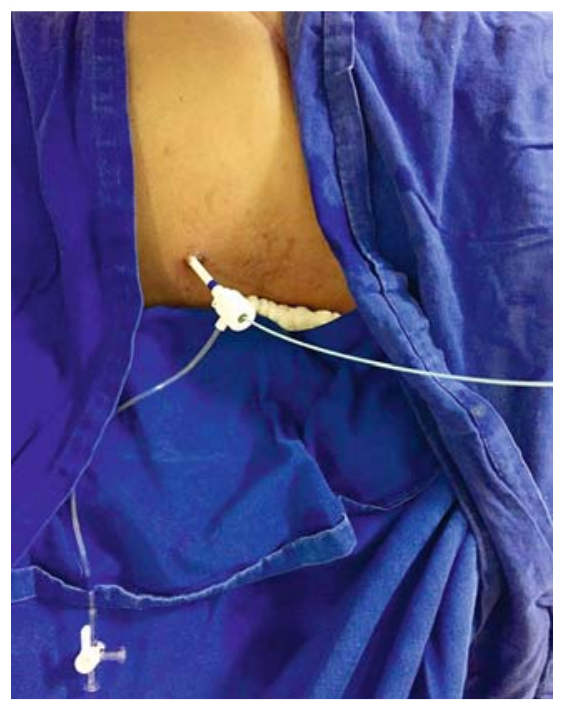

- Fig. 3 Visualization of a $12 \mathrm{Fr}$ sheath through the right percutaneous transhepatic biliary drain insertion site.

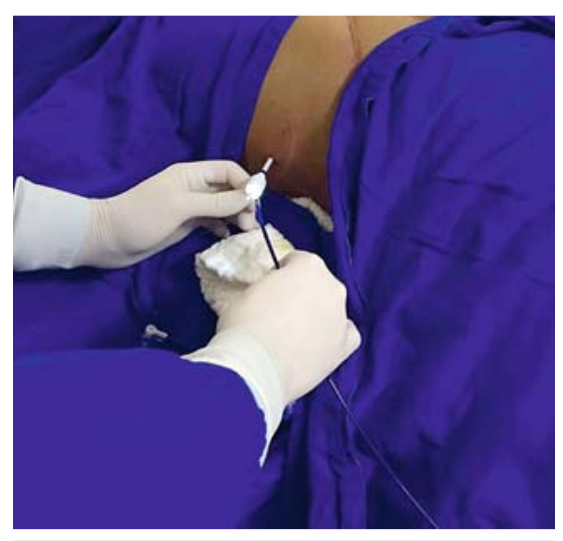

- Fig. 4 Insertion of the Spyscope (Boston Scientific, Marlborough, Massachusetts, USA) through the percutaneous access.

A 40-year-old woman presented with recurrent cholangitis due to right hepatolithiasis ( $\triangleright$ Fig. 1). Past history included a failed ERCP, and subsequent cholecystectomy with biliary exploration at another hospital. First, left PTBD was performed to improve the patient's clinical status. A multidisciplinary team then decided in favor of surgical bile duct ex-

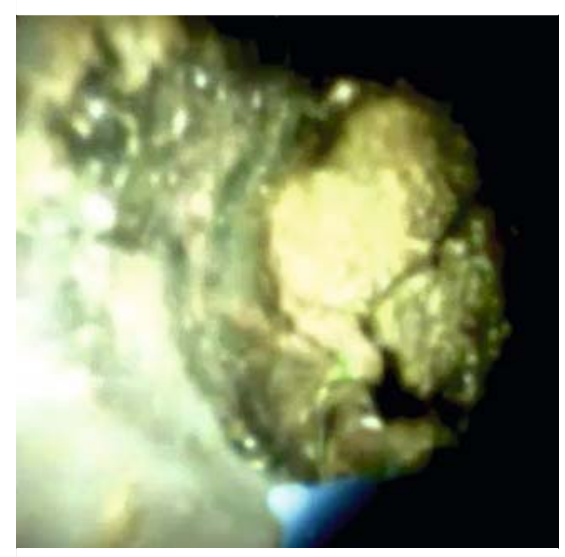

> Fig. 5 Cholangioscopy-guided laser lithotripsy.

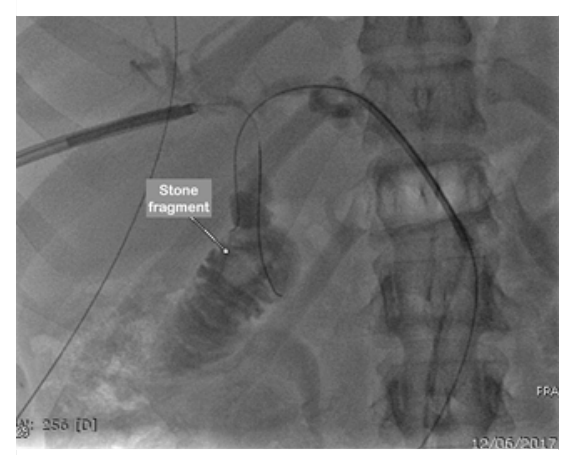

- Fig. 6 A large stone fragment was mobilized through the hepaticojejunostomy.

ploration with hepaticojejunostomy; however, the right intrahepatic stone could not be identified, even with intraoperative ultrasound. Biliary exploration through the PTBD drain was scheduled for the postsurgical recovery period. Meanwhile, cholangitis recurred, and the patient underwent urgent right PTBD following discovery of a $1.7 \mathrm{~cm}$ biliary stone, which had impacted in the confluence of the right anterior and posterior sectoral biliary ducts ( $\mathbf{F i g . 2}$ ). Balloon fragmentation was attempted, but was not successful. In addition, a basket was not considered to be a safe method of retrieval because of the size of the stone. 


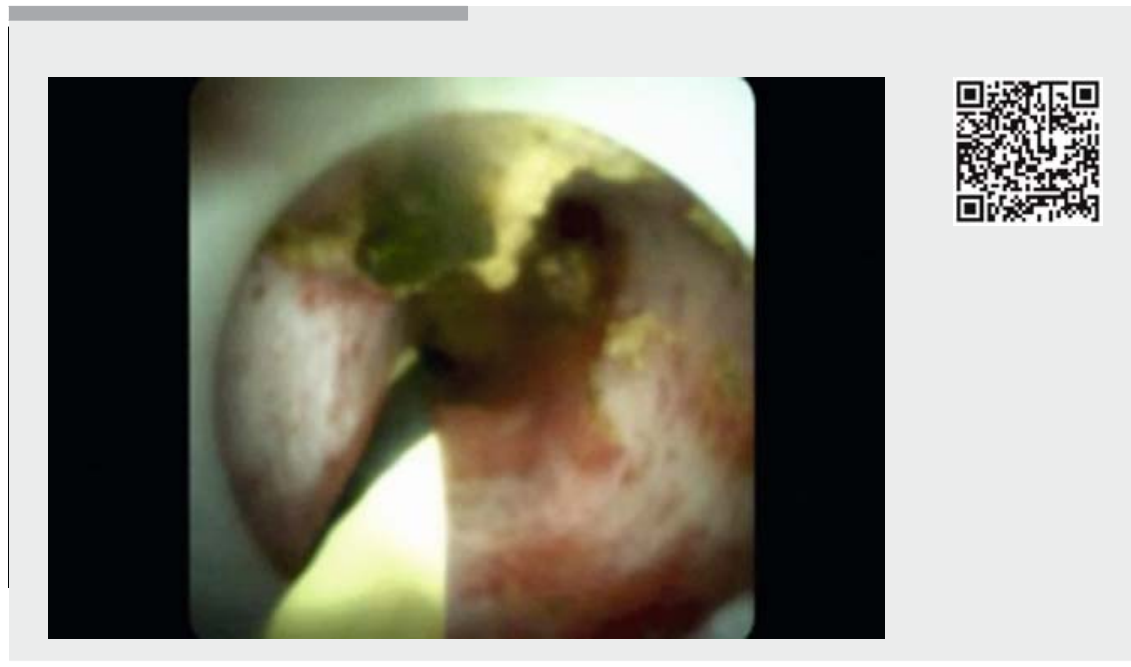

Video 1 SpyGlass (Boston Scientific, Marlborough, Massachusetts, USA) percutaneous transhepatic cholangioscopy-guided lithotripsy.

After clinical recovery of the patient, the multidisciplinary team opted for a hybrid procedure involving access to the biliary tree through the right PTBD site and cholangioscopy-guided laser lithotripsy using the intraductal cholangioscopy system SpyGlass DS (Boston Scientific, Marlborough, Massachusetts, USA). Informed consent was obtained.

The procedure was performed under general anesthesia, and prophylactic ciprofloxacin $400 \mathrm{mg}$ was given intravenously. The previously inserted biliary drain was exchanged for a $12 \mathrm{Fr}$ sheath ( $\vee$ Fig.3), allowing the insertion of the Spyscope under fluoroscopic and direct visualization (\$Fig.4). A large impacted stone causing biliary ulceration was visualized. Lithotripsy was performed using Holmium laser with power output at 10 W ( Fig. 5, \Video 1). Stone fragments were mobilized through the hepaticojejunostomy (\$ Fig.6), and new biliary drains were inserted bilaterally. The total procedure time was 58 minutes. The patient developed postoperative cholangitis, which was treated successfully with antibiotics.

Endoscopy_UCTN_Code_TTT_1AR_2AH
Competing interests

None

The Authors

Tomazo Franzini ${ }^{1}$, Leandro Cardarelli-Leite ${ }^{2}$, Estela Regina Ramos Figueira', Flávio Morita ${ }^{1}$, Fernanda Uchiyama Golghetto Domingos ${ }^{2}$, Francisco Cesar Carnevale ${ }^{2}$, Eduardo Guimarães Hourneaux de Moura'

1 Department of Gastroenterology, Hospital das Clinicas from University of São Paulo School of Medicine, São Paulo, Brazil

2 Department of Radiology, Hospital das Clinicas from University of São Paulo School of Medicine, São Paulo, Brazil

\section{Corresponding author}

\section{Tomazo Franzini, MD, PhD}

Department of Gastroenterology, Hospital das Clinicas from University of São Paulo School of Medicine, Av. Dr. Eneas de Carvalho Aguiar, 255 - Predio dos Ambulatorios 5th floor, 05403-000 São Paulo, Brazil Fax: +55-11-26617579 tomazof@uol.com.br
[1] Franzini TA, Moura RN, de Moura EG. Advances in therapeutic cholangioscopy. Gastroenterol Res Pract 2016; 2016: 5249152

[2] Mori T, Sugiyama M, Atomi Y. Gallstone disease: management of intrahepatic stones. Best Pract Res Clin Gastroenterol 2006; 20: $1117-1137$

[3] Cannavale A, Bezzi M, Cereatti F et al. Combined radiological-endoscopic management of difficult bile duct stones: 18-year single center experience. Ther Adv Gastroenterol 2015; 8: 340 - 351

[4] Tellez-Avila FI, Duarte-Medrano G, Valdovinos-Andraca F et al. Percutaneous laser application using the SpyGlass system in a patient with intrahepatic lithiasis, liver cirrhosis, and surgically altered anatomy. Endoscopy 2016; 48: E49-50

[5] Bhandari S, Bathini R, Sharma A et al. Percutaneous endoscopic management of intrahepatic stones in patients with altered biliary anatomy: a case series. Indian J Gastroenterol 2016; 35: $143-146$

\section{Bibliography}

DOI https://doi.org/10.1055/s-0043-117943

Published online: 19.9.2017

Endoscopy 2017; 49: E292-E293

(C) Georg Thieme Verlag KG

Stuttgart · New York

ISSN 0013-726X

\section{ENDOSCOPY E-VIDEOS}

https://eref.thieme.de/e-videos

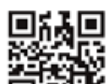

Endoscopy E-Videos is a free access online section, reporting on interesting cases and new techniques in gastroenterological endoscopy. All papers include a high quality video and all contributions are freely accessible online.

This section has its own submission website at https://mc.manuscriptcentral.com/e-videos 